\title{
Research of Improving IT Education Quality and Developing Cooperation between the Cross-strait Colleges
}

\author{
Yongze Fang ${ }^{1,}$, , Yongjie Zhong ${ }^{2, b}$, Jie Chen ${ }^{3, c}$ and Weiwei Wang ${ }^{4, d}$ \\ 1,2,3,4 Jimei University, Xiamen, Fujian, China 361021

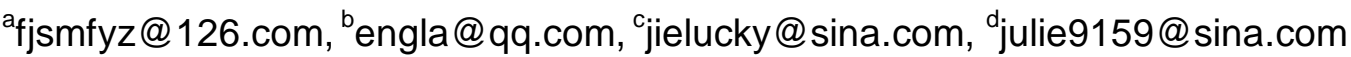

Keywords: IT education; colleges; both sides of the Taiwan Straits; exchange and cooperation Abstract. This paper summarizes the main characteristics and breakthroughs of exchange and cooperation in higher education between the both sides of Taiwan Straits for the past 6 years; analyzes how to improve IT education quality through exchange and cooperation between cross-strait colleges, as well as the joint education programs of the both sides of straits; and at last, this paper analyzes the obstacles that the Taiwan colleges are faced in recruiting students from the mainland and the difficulties that the graduators face in hunting jobs.

\section{Introduction}

There is a strong complementarity in IT educational resources from the both sides of Taiwan straits. Most IT majors in the common colleges in Fujian province are upgraded from specialized secondary school or even newly founded in the 1980's, with a low starting point, quick expansive speed and a weak foundation. Some IT enterprises from Taiwan and some colleges have been internationally advantageous, but a declining birth rate in Taiwan has resulted in a plethora of higher education resources, so it is urgent to expand its enrollment. If the education resources from the both sides can be integrated, then resource sharing can be realized, the advantages can be complementary, and the two-way benefit can be fulfilled. On the other hand, Taiwan-funded enterprises run in the mainland have been developing in a very large scale, so, they also need a lot more IT talents who can be accustomed to the characteristics of those Taiwan-funded companies. It is emergent to research how to train IT talents through the high educational cooperation from the two sides of the straits.

In recent 6 years, cross-strait higher education cooperation has made a breakthrough progress, with a tremendous development space in the future. This paper, based on a systematic investigation, makes a brief retrospective outlook and analysis of the main development and characteristics of the cross-strait educational cooperation, and searches for the ways to boost IT teaching quality and graduates' competitiveness in job market through the cross-strait exchange and cooperation.

\section{A Retrospective Outlook of the Development and an Analysis of the Characteristics of the Cross-strait Higher Education Cooperation}

The Colleges from Fujian and Taiwan Have Innovated Forms to Train Students from the Mainland in a Large Scale. In the process of gradually opening up the cross-strait policies, educational cooperation should explore some suitable forms so as to adapt to the cross-strait real policy environment, really satisfy the objective requirements from the local economy and society. During the 6 years, the colleges from Fujian and Taiwan have carried out a variety of cross-strait collegiate cooperation in the form of different programs, initiating the history of selecting students from the mainland to study in Taiwan colleges in organized groups and batches. From 2009 to 2013, 32 colleges in Fujian cooperate with more than 50 colleges from Taiwan to train specialized talents jointly concerning many different majors, with a scale of 26,000 students $^{[1]}$. The main majors concerned are those strongly needed by the society, or those with a weak foundation in Fujian, such as information technology, advanced manufacturing.

For example, "college-college-enterprises" program adopts a double college learning model, which is, during the four years of undergraduate studying, students will continue their learning at the 
cooperative college in Taiwan for one year. Taiwan-funded companies take an all-round participation in training the students, in accordance with the job requirements from Taiwan-funded companies' professional vacancies. It is stipulated that the professional courses drawn from Taiwan colleges should not be less than $1 / 3$, and that teachers from Taiwan colleges should not take less than $1 / 4$ professional courses.

Taiwan Breaks the History to Enroll Students from the Mainland. Since 2011, Taiwan initiated to enroll students from mainland, including undergraduates, graduates, and doctors. Furthermore, it is the first time for Taiwan to acknowledge the certificates from 41 mainland colleges, which is referred to as the milestone of Taiwan. It has three aims: the first is to boost a mutual understanding of the young people from cross-straits; the second is to improve a competition and cooperation between the students from Taiwan and the mainland, making the Taiwan students feel more challenges in their learning process; the third is that the plethora of higher educational resources in Taiwan can be fully exerted, thus turning Taiwan higher education into an industry that can be exported.

In 2011 and 2012, the enrolled students from mainland who really registered in Taiwan colleges amounted to only half of the planned recruitment total. In 2013 and 2014, the situation improved, but the planned enrollment totality is still unaccomplished. Why there is a gap between the real recruitment situation and what the Taiwan colleges expect? The reasons should be researched out.

It is investigated that the initial reasons are: there is a lack of mutual understanding between the people from the both sides of the straits; in addition, the related procedures are very complex and time-consuming. In the mainland, common families don't have an even basic understanding of Taiwan colleges, so what they do is make a temporary and superficial survey when selecting a Taiwan college and making an enrollment decision. Furthermore, they have a lot of other anxieties, such as how to live there, how to learn and find a job after graduation? Eventually, they will give up their choices for Taiwan colleges.

It is ruled that students from the mainland are not allowed to work in Taiwan Island, so they will encounter many difficulties in finding a job after graduation. Mainland students should leave Taiwan Island and go back to find a job while graduation is coming; however, that time period is also for them to arrange their graduation dissertation. Mainland enterprises barely understand Taiwan colleges and their graduates; employers and employees are not smooth in information exchange, and the graduates should come and go back to the mainland for many times. This can arouse great pressure on the mainland students financially, in time arrangement, in energy and psychologically. The graduates from mainland hope that those concerned sides can make some research and supply more convenience and help to them.

\section{Strengthening Students' IT Engineering Ability According to the Enterprise Need}

Most IT majors in the common colleges in Fujian are upgraded in the 1980's from specialized secondary school or even newly founded, with a low starting point, quick expansive speed and a very weak foundation. It is very significant to analyze the qualities of Fujian IT education, draw some lessons from Taiwan IT teaching experiences, and combine the requirements from Taiwan-funded IT enterprises, so as to improve the teaching quality.

Analyzing Method to Train Students' Engineering Abilities. Currently, the most extrusive problem of IT majors in Fujian common colleges is that the college graduates don't have matching engineering competencies to satisfy the requirements from the companies. The reason lies in that engineering education is not closely related to industrial circles. So, it is quite urgent to strengthen nurturing students' engineering abilities.

In IT major teaching, the channels to train engineering abilities can be analyzed by a 3-D structure: course-knowledge-ability ${ }^{[2]}$. First, leaders responsible for major construction and teachers of different courses should break up all detailed ability demands required for the major graduates into different courses when jointly formulating the major plans according to specific major goals. then, every course teacher will decide the connected knowledge and contents in accordance with this layout; analyze the 
characteristics of each knowledge unit in their course, and the corresponding function in training the engineering abilities, so as to choose and adopt different teaching style, such as problem-oriented learning, projection-oriented learning, and case-oriented learning, making the students understand what they have learned and equip them with engineering abilities through a series of learning activities; eventually, form the different teaching scheme directed at respective knowledge unit. The last, every teaching scheme from all major courses should be put together, and an assorted check-up should be made to find out how every engineering ability is trained through which course, which knowledge unit, and which kind of training. Thus the training effects would be evaluated, and course system could be thereafter optimized.

Cross-strait colleges should learn from each other about the advanced teaching thinking and models, jointly carry out teaching resources' construction from the aspects of course and learning materials, eventually establishing a high-level teaching staff and teaching model.

Education Facing Taiwan-funded Enterprises. IT technologies and IT industries in Taiwan have great advantages. Among the Top 250 ICT (Information and Communication Technology) firms in the world, 18 firms are from Taiwan, ranking the $3 \mathrm{rd}$ place in its total number in $2010^{[3]}$. With a continuous expansion of Taiwan-funded companies' investing into mainland industries, currently the west bank of the straits has changed into a very significant place of Taiwan IT companies. Taiwan-funded enterprises need a lot of IT talents who are familiar with and can also adapt to the Taiwan companies' operational model.

In addition to engineering knowledge and abilities, the key point for the training of college students is comprehensive qualities such as professional morals, innovative awareness, teamwork and communication, adapation to changeable environment and pressrure. Presently, colleges from Fujian should pay attention to the big differences between campus culture and Taiwan-funded entreprises culture, teaching the students how to adapt to its company culture initiatively.

In the high speed development, Taiwan entreprises have formed their unique company culture, with very distinctive characteristics. The foundation of Taiwan company culture lies in three qualities: passing on Confucian culture, making every effort to seek profits, modern management science from the west. These qualities are shown in many aspects. In their daily communication, they are very polite and humble, very loyal to the customers; they require their employees to work with high efficiency and high strength; in managing the employees, they are very strict with the employees according to principles and standards. These are very different from the campus culture which the Fujian college students are accustomed to. Consequently, the colleges should carry out quality extension education, making the college students well-regualted in their daily campus life and studies, be polite, be morally regulated, and understand well the companies' regulations, principles, moral perspectives, and the managing ways on how the superiors treat other employees. And it is important to boost their abilities for interpersonal communication, competition and cooperation, and well adapt to Taiwan-funded companies' management and working requirements.

\section{Thinking on the Joint Programs of Cross-strait Colleges}

The Joint Programs should Establish Brand Consciousness. In recent years, the "college-college-company" programs have realized a leaping development in the form innovation and enrollment size in cross-strait educational cooperation. These programs should be consolidated and improved. As its tuition fee is higher than other enrollment types in mainland, and more colleges are launching the similar programs, the enrolled students' qualities may be undermined if program brands can't be set up as soon as possible. Presently, the brand and quality awareness should be intensified, and a balanced development should also be achieved in scale and teaching qualities.

Exerting the Students' Advantages of Joint Programs to Boost Taiwan-funded Enterprises' Development and Expand the Employment Scale. Taiwan-funded enterprises have developed very vigorously in mainland, in great need of a large scale of talents who are familiar with Taiwan culture, technology and managing model. Those mainland students going to study in Taiwan and those who are 
trained through joint programs are advantageous in this aspect. Connected departments should do some targeted work to deal with employment service, and the colleges should emphasize to recommend the programs' traits when students come to graduate. This can not only help students find suitable jobs, but also help to establish brand image very quickly, getting inspection and development through practices. The main investing places of Taiwan businessmen are Fujian, Jiangsu, Guangdong, Shandong, Zhejiang and Shanghai. When introducing IT graduates, such features as the highly investment-focused areas and industrial concentration should be utilized, thus taking a more efficient way to recommend these IT major graduates. Their aim is not only oriented at large-scale Taiwan-enterprises, but also at medium-sized and small Taiwan companies. These enterprises are also eager to have talents and more importantly, they can supply a lot of jobs available. The students from mainland who are going to Taiwan for studying are not allowed to work in Taiwan Island due to the restriction from Taiwan policies, so they need to be given more help and preferential policies considering their difficulties and advantages.

\section{Conclusions}

Presently, cross-strait higher education should actively promote form innovation and increasing efficiency, supplying better policy environment and service for the cross-strait students, and improve higher education cooperation from the both sides of the straits, which is implemented through the healthy interaction from the aspects of students, colleges, the administrative authorities from the both sides. IT majors of Fujian common colleges should pay more attention to nurturing students' engineering competencies, and strengthening the cross-strait collegiate exchange and cooperation can boost IT education qualities.

\section{Acknowledgements}

This work is financially supported by the Science and Technology Project (soft science) of Fujian Province of China (2013R0078).

\section{References}

[1] Fujian Department of Education. An evaluation report on intermediate inspection of the pilot program "exchanges and cooperation reform in Cross-strait colleges (for undergraduate colleges) " (in Chinese)

[2] Yongze Fang, Research of the Model to Foster Engineering Students'Ability and the Assistant Analyzing System, IC3ME2014, June 2014, Guangzhou, China

[3] Council for Economic Planning And Development, among the top 250 ICT enterprises in the world, 18 are located in Taiwan, ranking a third place in its total number [EB/OL]. http://www.taiwantrade.com.tw/CH/bizsearchdetail/4463854/C/ (in Chinese)

[4] Amparo Camacho, Javier Paez. Modern curricula design for engineering programs, http://www.ineer.org/Events/ICEE2008/full_PaPers/full_paPer266.Pdf

[5] Brent Wilson, Martin Ryder, Distributed Learning Communities: an Alternative to Designed Instructional System, http://www.adraptis.com/voithima/theoretic/distributed_learning.pdf

[6] Erik De Graaff, Wim Ravesteijn, Training complete engineers: Global enterprise and engineering edueation http://www.tandfonline.com/doi/abs/10.1080/03043790110068701 